\title{
Editorial
}

\section{La caída de los precios del petróleo y sus efectos en la economía colombiana}

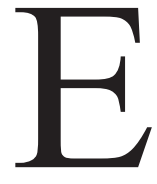

1 precio del petróleo ha bajado considerablemente en los últimos nueve meses. La variedad Brent, referencia para Colombia, descendió de 115 dólares el barril a 55 dólares, entre junio de 2014 y marzo de 2015. El precio más bajo se registró el 28 de enero del presente año, cuando el crudo se cotizó a 44,45 dólares el barril. Este descenso tan rápido y tan pronunciado no se había presentado en el pasado. La variación de los precios y la forma en que lo ha hecho se debe tanto a factores de demanda como de oferta.

La demanda se ha reducido significativamente, comportamiento que se explica, entre otras razones, por la recesión económica mundial que comenzó en 2008, y, sobre todo, por el bajo crecimiento de China, que venía registrándose a más del $10 \%$, pero actualmente lo hace a un $7 \%$. Asimismo se destacan el desarrollo de nuevas tecnologías orientadas al ahorro de energía, el incremento en el uso de energías alternativas, como la eólica y fotovoltaica, y la mayor participación de los biocombustibles en el mercado de energéticos.

Por otra parte, la oferta se ha incrementado debido a la utilización de nuevas técnicas de extracción (fracturación hidráulica - fracking), en especial, en los EE.UU., país que ha aumentado su producción hasta 9,42 millones de barriles diarios (promedio del mes de marzo de 2015), exportando en diciembre pasado 442000 barriles por día. A lo anterior se agrega el aumento de la producción de países como Arabia Saudita, Irak y Libia -el primero la ha incrementado y actualmente produce 11 millones 525000 barriles diarios, hecho que lo ubica como el mayor productor del mundo, por las cuantiosas reservas de que dispone y por los bajos costos en la extracción del crudo (en promedio 6 dólares el barril)-, el desacuerdo dentro de la Organización de Países Exportadores de Petróleo (OPEP) para reducir la producción y, así, disminuir la oferta, y, en consecuencia, desatar el incremento del precio del crudo. Cabe subrayar que mientras Venezuela e Irán son partidarios de bajar la producción, Arabia Saudita y Kuwait se oponen a esta medida.

Para la economía colombiana la reducción del crudo ha sido impactante en diferentes frentes. La actividad de exploración, según Francisco Lloreda, presidente de la Asociación Colombiana de Petróleo (ACP), está prácticamente estancada, dado que la actividad sísmica ha descendido en $92 \%$ y la de pozos exploratorios, en 82,6 \%. En lo corrido del año (15 de mayo de 2015) se han perforado nueve pozos, mientras que en el año pasado fueron 52. Según el dirigente gremial, la sostenibilidad del millón de barriles diarios -que es lo que actualmente produce Colombia- está en riesgo. Además, la caída de los precios internacionales del petróleo reducirá el crecimiento económico entre 1,5 a $2 \%$ en el presente año. Este comportamiento 
se explica debido a que las exportaciones del crudo representan un $50 \%$ del total de ventas al exterior y un $20 \%$ de los ingresos fiscales de la nación.

De hecho, el déficit de 6293 millones de dólares en la balanza comercial es resultado de lo anterior. En el último trimestre de 2014 fue más impactante: el déficit en esos tres meses ascendió a 43986 millones de dólares, observándose que los precios del petróleo bajaron, pero sin alcanzar el nivel mínimo. En los dos primeros meses del año en curso, el déficit fue de 3038 millones de dólares, monto bastante preocupante, pues acarrea una subida de la tasa de cambio, lo cual, además de beneficiar a algunos productos exportables -si se mantiene en niveles muy altos-, es previsible que atice la inflación, dependiendo del componente importado, genere incertidumbre en la evolución de la economía, y, de paso, altere las decisiones de los inversionistas.

Simultáneamente, la caída de los precio del petróleo afecta, según el ministro de Trabajo, Luis Eduardo Garzón, a 110000 empleos tanto directos como indirectos. A los directos, debido a que las petroleras han recortados sus planes de inversión, y a los indirectos (transportadores, ingenieros, firmas de montaje y perforación, entre otras), porque sus actividades (a fínales de abril) se redujeron en $47 \%$, con el agravante de que a las empresas petroleras les están solicitando que reduzcan sus tarifas para poder continuar su relación comercial. Es tan preocupante la situación, que, según el ministro de Trabajo, los sindicatos afiliados a la Confederación General de Trabajadores (CGT) están dispuestos a postergar sus prestaciones laborales, siempre y cuando no sean despedidos de sus puestos de trabajo.

En materia fiscal la situación es crítica, si se tiene en cuenta que una quinta parte de los ingresos de la nación depende del petróleo, lo que ha llevado al Gobierno nacional a reprogramar el presupuesto para enfrentar la baja en el precio del petróleo. Según el ministro de Hacienda, Mauricio Cárdenas, se prevé en el presente año un déficit fiscal de 9 billones de pesos. La mitad de este se financia con recursos de la última reforma tributaria y la otra mitad con más endeudamiento, lo que elevará el déficit de 2,3 a 2,8\% del PIB. Este déficit es explicable, en buena parte, por la caída de los precios del petróleo, lo que necesariamente se traducirá en una reducción de las utilidades de Ecopetrol, con mayor razón si se tiene en cuenta que la petrolera estatal le proporcionó en 2014 a la nación dividendos por más de 9 billones de pesos.

En términos generales, la caída de los precios del petróleo repercutirá en la economía en su conjunto. Variables como empleo, crecimiento económico, ingresos de la nación, regalías para los departamentos, entre otras, se verán afectadas, imponiéndose la necesidad de analizar diferentes alternativas que aminoren el impacto. En la medida en que la oferta del crudo se incremente por la extracción de este a través de métodos no convencionales, es imposible que el petróleo alcance los altos precios que tuvo hace un año.

Luis E. Vallejo Zamudio

Director de la Revista Apuntes del CENES 